\title{
Balansen mellan att uppmuntra och ställa krav. En reflektion över studenters uppsatsskrivande i relation till stress och stöttning
}

\author{
Maria Zackariasson \\ Södertörns högskola, Stockholm
}

\begin{abstract}
När studenter ska skriva sin första stora uppsats, det vill säga det som i högskoleförordningen betecknas "självständigt arbete", möter de delvis andra krav och förväntningar än de stött på tidigare under sin utbildning. Det kan gälla till exempel hur självständiga de förväntas vara, men också att de ska skriva en text som inte bara visar vad de själva har lärt sig utan som också andra kan lära sig av. För några är detta en spännande utmaning, som de ser fram emot, men för andra kan uppgiften framstå som skrämmande och stressande. Hur ska man som kursansvarig kunna entusiasmera och motivera studenter för uppgiften att skriva sitt självständiga arbete, när man samtidigt vill få dem att inse att uppsatsarbetet kan vara både svårt och utmanande och att de måste arbeta hårt för att klara av det?

I denna artikel använder jag scaffolding som teoretisk utgångspunkt för att reflektera över detta, i ett resonemang runt vad stress och stöttning kan innebära i detta sammanhang och hur relationen dem emellan kan se ut. Jag utgår från mina erfarenheter som kursansvarig på en självständigt arbete-kurs på ett av lärarutbildningens program.
\end{abstract}

Nyckelord: självständiga arbeten, uppsatsskrivande, scaffolding, stöttning, stress, lärarutbildning

"Jag hörde från studenterna att de tyckte att du skrämde upp dem rejält igår! Du satte tydligen skräck i dem!" Min kollega tittade leende in på mitt arbetsrum när hon gick förbi. Hon hade precis haft föreläsning för lärarstudenterna på kursen i vetenskapsteori och metod. Dagen innan hade jag en introduktionsföreläsning inför den kommande uppsatskursen för samma studentgrupp. Var det det intrycket de hade med sig efter föreläsningen? tänkte jag lite bekymrat. Det var kanske inte så lyckat. Vad hade jag egentligen sagt och gjort?

Som jag mindes det hade jag som vanligt lagt mycket tid och energi på att försöka väcka engagemang hos studenterna. Jag var fullt medveten om att det inte alls var självklart för alla som satt där i salen varför de egentligen skulle skriva självständiga arbeten. Därför hade jag pratat om hur de nu skulle få chansen att fördjupa sig i något de kanske tyckte de fått för lite av under utbildningen. Jag hade uppmanat dem att utgå från situationer, problem och idéer de fått när de varit ute på VFU, alltså verksamhetsförlagd utbildning, och understrukit att uppsatserna inte bara var något de behövde göra för att få ut sin examen utan att det också var en möjlighet att se skolvardagen ur ett annat perspektiv.

Med tanke på att det var första gången de skulle skriva ett självständigt arbete av detta slag, och att själva uppsatskursen på många sätt var annorlunda än det mesta de hade gjort hittills

*Författarkontakt: maria.zackariasson@sh.se 


\section{Maria Zackariasson}

under sin utbildning, hade jag också, precis som jag brukade göra, gått igenom processen steg för steg: från deras första val av ämne och tilldelning av handledare till de avslutande ventileringarna. Dessutom hade jag entusiastiskt påpekat att de nu för första gången inte skulle skriva enbart för att lära sig något eller visa att de lärt sig något, utan att de skulle gå ett steg vidare och skriva något som andra förhoppningsvis kunde lära sig av. Precis som tidigare terminer hade jag fått mängder av frågor från studenterna som jag hade försökt besvara på bästa sätt, och jag hade försökt bemöta den oro de gav uttryck för och lugna dem inför vad som komma skulle. Till exempel genom att dementera och nyansera rykten och berättelser som de verkade ha hört från studenter på tidigare terminer om hur många som brukade bli underkända, handledare som inte gjorde sitt jobb eller hur arbetskrävande kursen var.

Jag tyckte nog att jag under hela föreläsningen hade försökt motivera och entusiasmera studenterna på olika sätt. Men det är klart, jag hade också varit mycket tydlig med att det ställdes delvis nya krav på dem under den kommande terminen. Både för att de nu på termin sju faktiskt befann sig på avancerad nivå och för att de i och med uppsatskursen förväntades arbeta mer självständigt än förut. Jag hade pratat en hel del om att de själva hade stort ansvar för arbetet och för uppsatsens kvalitet, liksom om de utmaningar de kunde tänkas stöta på under vägen. "Se till att starta i tid", hade jag sagt. "Det kanske ser ut i schemat som att ni har massor av tid, men det går mycket fortare än ni tror!" ”Ni kommer att få jobba hårt - räkna med att det blir en tuff termin." Ur det perspektivet hade jag, i ärlighetens namn, också i någon mån strävat efter att skrämma eller åtminstone stressa upp dem lite inför det kommande arbetet. Så helt fel hade kanske inte studenterna ändå.

\section{ETT DILEMMA}

Exemplet ovan är hämtat från introduktionsföreläsningen på en kurs på ett lärarutbildningsprogram som jag under flera år var ansvarig för, där studenterna skulle skriva sitt självständiga arbete, det vill säga den större uppsats de skrev precis i slutet av utbildningen. Även om just den här episoden särskilt tydligt visade att det kunde vara en svår balansgång mellan att å ena sidan entusiasmera och motivera studenterna för uppsatsarbetet, och å andra sidan få dem att inse att uppsatsarbetet kan vara både svårt och utmanande och att de måste arbeta hårt för att klara av det, så var det ett dilemma jag som kursansvarig brottades med på flera sätt och i olika sammanhang under alla de gånger jag hade kursen.

Jag upplevde det ofta som svårt att hitta balansen mellan att uppmuntra och stötta studenterna på olika sätt för att motivera dem och bidra till deras tilltro till att de skulle klara av uppgiften, och att kommunicera till studenterna att de fick räkna med att kursen skulle vara krävande och intensiv på ett sätt många av dem inte var vana vid, vilket i sig kunde upplevas som stressande eller skrämmande för studenterna. Mina erfarenheter gav upphov till frågor runt hur man kan hantera detta dilemma på bästa sätt, vad stress och stöttning kan innebära i relation till studenters uppsatsskrivande och hur relationen mellan dem ser ut. I det följande ska jag utveckla några reflektioner runt detta, med utgångspunkt i forskning dels runt studenters stress, dels runt stöttning, eller scaffolding.

\section{STUDENTER OCH UPPSATSSTRESS}

Vad menar vi då när vi talar om stress i detta sammanhang? Det finns förstås många typer av stress, allt från den som uppstår när individen upplever sig ha för mycket att göra eller för lite tid att göra det på, till den stress som kan uppstå när individen kliver utanför sin egen komfortzon och därigenom genomgår en utveckling på ett personligt eller intellektuellt plan. I den befintliga 
forskningen finns det en del studier som har tittat på studenters stressnivåer, och dessa uppmärksammar ofta i första hand den negativa stressen, som är kopplad till arbetsbelastning och olika kringfaktorer som kan leda till ökad stress hos studenter. Fokus ligger som regel på att försöka minska studenternas stressnivåer, som alltså huvudsakligen ses som ett problem (t.ex. Feldt \& Updegraff, 20I3; Galbraith \& Brown, 20II; Mills, Krouse, Rossi-Schwartz \& Klein, 20I7).

Med utgångspunkt $i$ att högre utbildning optimalt sett ska leda till personlig utveckling och djuplärande hos studenterna och att detta är något goda lärare gärna ska bidra till och sträva efter, vilket flera forskare på fältet argumenterar för (se t.ex. Bain, 2004; Ramsden, 2003), är emellertid den typ av potentiellt mer positiv stress som kan uppstå när man kliver utanför sin komfortzon och genomgår utveckling också högst relevant att diskutera i detta sammanhang. Just uppsatsskrivandet har stor potential att bidra till personlig utveckling och djuplärande hos studenterna, inte minst genom att det är en möjlighet att genomföra en mindre forskningsuppgift, i linje med Healeys (2005:I3) beskrivning av forskningsbaserad undervisning. Här får de möjlighet att fördjupa sig i ett ämne de intresserar sig för, och reflektera runt och analysera detta på olika sätt. Samtidigt uppfattar många studenter uppsatsarbetet, och de krav och förväntningar som är knutna till det, som något nytt, annorlunda och på många sätt stressande och svårt att hantera.

Varför är det då så? Ja, det är något speciellt att skriva den här typen av arbeten, av flera skäl. Bland annat för att studenterna har ett markant större ansvar för sitt eget arbete och för att driva det framåt på ett självständigt sätt än de som regel har på andra kurser under sin utbildning. Flera forskare har påpekat att modeller för lärande och undervisning som har ett stort fokus på självständighet och på lärandeprocesser snarare än yttre kontroll, kan upplevas som frustrerande av individerna, inte minst av dem som av olika anledningar upplever uppgiften de har framför sig som svår och oöverstiglig (se Barkat, 20I4; Kicken, Brand-Gruwel \& van Merriënboer, 2008; Thoonen, Sleegers, Peetsma \& Oort, 20II). Att förväntningarna om större självständighet kan leda till stress och oro var något jag regelbundet upplevde bland studenterna som skulle skriva självständigt arbete och det har också lyfts fram i forskning om uppsatsskrivande på den här nivån (t.ex. Light, Cox \& Calkins, 2009:I5sf).

En annan aspekt som kan bidra till stress och oro bland studenter på den här typen av kurser är att det självständiga arbetet ofta framställs som, eller uppfattas som, en slags slutprodukt, där studenten ska kunna använda det hon eller han lärt sig tidigare under utbildningen och vidareutveckla det. Det är med andra ord mycket som står på spel om man misslyckas, både när det gäller den energi och det arbete studenten lagt ner i själva uppsatsarbetet, och när det gäller det arbete hon eller han har lagt ner under hela den utbildning som lett fram till denna kurs. Som också Light, Cox och Calkins (2009:I55) påpekar, finns det således en dubbelhet i uppsatsskrivande av det här slaget, såtillvida att den här typen av uppsats är en av de delar i utbildningen som har störst möjlighet att leda till personlig förändring, samtidigt som det kan få känslomässiga konsekvenser att det är så mycket investerat i den.

Att känslomässiga aspekter kan vara viktiga inslag $\mathrm{i}$ just handledning och andra aspekter av produktionen av större skriftliga arbeten har lyfts fram av flera forskare på fältet (t.ex. Clegg, 2000; Cotterall, 20I3; McCormack, 2009; Todd, Smith \& Bannister, 2006). Det innebär förstås inte att uppsatsarbetet enbart inkluderar negativa känslor. Även entusiasm inför uppgiften, glädje över det man gör och stolthet över det man åstadkommit kan vara centrala delar i studentens uppsatsprocess (jfr Zackariasson, 20I8). Men olika studier av handledning av studenter och doktorander har ändå visat att just oro, rädsla och ångest hör till de känslor som ofta är mest framträdande i dessa sammanhang (Castello, Inesta \& Monereo, 2009; Todd et al., 2006; 


\section{Maria Zackariasson}

Zackariasson, 20I8). Det här är något vi som lärare, handledare eller kursansvariga, behöver vara medvetna om och förhålla oss till.

Den oro lärarstudenterna gav uttryck för under min introduktionsföreläsning i exemplet ovan, och som jag också brukade möta i olika sammanhang under kursens lopp, var alltså inte unik på något sätt, utan något man snarast kunde förvänta sig. Då kan man förstås undra varför jag envisades med att så tydligt kommunicera till studenterna att det inte var någon lätt uppgift de hade framför sig. Varför lade jag så stor vikt vid de problem de kunde tänkas stöta på och att kraven nu var högre än de hade varit på tidigare kurser? Skulle det inte vara bättre att vid ett sådant introduktionstillfälle tona ner de potentiella svårigheterna och utmaningarna, så att studenterna gav sig in i arbetet med obruten entusiasm?

Jo, det är förstås en fullt rimlig synpunkt. Samtidigt såg jag från min position som kursansvarig påtagliga risker med att underkommunicera arbetsbördan, de begränsade tidsramarna och det egna ansvaret. Dels för att det, i min erfarenhet, ökade sannolikheten för att alltför många studenter inte skulle bli färdiga i tid, dels för att det kunde leda till att de blev upprörda för att kraven på dem i slutändan var betydligt större än de hade förespeglats. Väl att märka var det ingen självklarhet att studenterna skulle klara det inom tidsramarna. Tvärtom var det varje termin ett antal studenter som antingen inte lade fram uppsatsen alls för att de inte hunnit färdigt, eller som inte lyckades uppnå den nödvändiga kvalitetsnivån och därmed fick uppsatsen underkänd. Att oproblematiserande säga att detta är visserligen svårt, men ni kommer att fixa det här, bara ni jobbar på, inga problem, riskerade således leda till ett antal besvikna studenter i slutet av uppsatsperioden, när det visade sig att det inte alls ordnade sig för dem allihop. Att försöka få studenterna att lyckas bemästra uppsatsskrivandet under utsatt tid var viktigt både för dem, så de kunde få ut sin examen, för mig som kursansvarig, så att jag skulle slippa massor av eftersläpande uppsatser nästföljande termin, och i förlängningen för lärarutbildningen och högskolan, så att studentprestationerna och genomströmningen kunde upprätthållas.

Å andra sidan finns förstås en risk att studenterna får en negativ inställning till det självständiga arbetet om man som kursansvarig alltför starkt betonar svårigheterna och utmaningarna, vilket var en orsak till att jag på olika sätt försökte balansera den i mina ögon nödvändiga betoningen av ökade krav och potentiella svårigheter med att väcka studenternas entusiasm och engagemang. Till exempel genom att visa på förbindelserna mellan det självständiga arbetet och deras erfarenheter av och framtida yrkesliv inom skolkontexten, och framhålla de möjligheter de nu hade att fördjupa sig i något de var intresserade av och göra en annan typ av uppgift än de gjort tidigare under utbildningen. Jag försökte med andra ord framställa de ökade kraven på bland annat självständighet och eget ansvar som något positivt. Samtidigt var jag inte naiv. Jag visste att många studenter tyckte att det självständiga arbetet verkade rätt oöverstigligt, eller helt enkelt bara ointressant, och att det för många var svårt och utmanande att lyckas ro det $\mathrm{i}$ land. För att de skulle kunna uppleva uppsatsarbetet som utvecklande och givande, och faktiskt lyckas slutföra det inom tidsramarna, skulle de behöva hjälp och stöd under resans gång.

\section{VAD INNEBÄR DET ATT STÖTTA?}

Studenterna fick också mycket stöd och hjälp under kursens gång, på olika sätt och i olika sammanhang. Hela vägen, från den utförliga studiemanualen och introduktionsföreläsningen, till det sista seminariet som var tänkt att förbereda dem på att genomföra ventilering och opposition, fanns det en rad inslag i kursen som syftade till att hjälpa dem i uppsatsskrivarprocessen. Men den önskan jag som kursansvarig hade att uppmuntra och stötta studenterna var samtidigt 
inte helt enkel att genomföra i praktiken. Delvis kan det sättas i relation till att det inte är självklart vad man menar med stöttning i detta sammanhang.

Som litteraturen visar finns det en rad olika förståelser och tolkningar av vad det innebär att stötta studenter i deras arbete. Även när man talar om stöttning i den mer specifika betydelsen "scaffolding", blir det tydligt att det är ett begrepp som har använts på en rad olika sätt och laddats med olika betydelser och innebörder (t.ex. Barkat, 20I4; Bodrova \& Leong, I998; Castillo-Montoya, 20I8; Ekholm, 20I2; Kicken et al., 2008; Knight \& Botting, 20I6; Korhonen, Ruhalahti \& Veermans, 20I8; Wass, Harland \& Mercer, 20II). van de Pol, Volman och Beishuizen (20I0) har gjort en grundlig genomgång av begreppet som är den jag utgår från i denna text. En av de aspekter de framhåller i sitt resonemang är att stöttning/scaffolding i sin teoretiska ursprungsbetydelse lade stor vikt vid studentens egen aktivitet. Det handlar med andra ord inte om att läraren hela tiden ska stötta studenten, utan om ett ömsesidigt givande och tagande. Det ska, idealt sett, vara ett gemensamt arbete, där både lärare och student bidrar till att bygga upp den imaginära "byggnadsställning" som är tänkt att ge stöd när studenten ska ta sig an något nytt, okänt och utmanande (van de Pol et al., 20IO:272).

För att stöttning/scaffolding ska kunna sägas äga rum, måste det enligt van de Pol et al. bygga på tre premisser: contingency, alltså kunskap om och anpassning till elevernas eller studenternas förkunskaper, fading, vilket innebär att läraren under processens gång drar sig tillbaka, och slutligen transfer of responsibility, det vill säga att ansvaret för uppgiften förs över till eleven eller studenten under processens gång. En annan grundläggande aspekt de framhåller är skillnaden på stöttningsmål (scaffolding intentions), det vill säga vad som ska stöttas, och stöttningsverktyg (scaffolding means), det vill säga hur stöttningen ska gå till. De poängterar att även om det finns många olika typer av ageranden som har potential att fungera som stöttningsverktyg, måste de grundläggande premisserna med contingency, fading och transfer of responsibility uppfyllas för att man ska kunna tala om stöttning i mer specifik bemärkelse, och inte bara stöd och hjälp i största allmänhet (van de Pol et al., 2010:274ff).

Som kursansvarig hade jag inte tänkt igenom och planerat kursupplägget med utgångspunkt i stöttning/scaffolding på det här sättet, men det fanns ändå gott om inslag i kursen som kan ses som exempel på det van de Pol et al. beskriver som både stöttningsmål och stöttningsverktyg. Hela det grundläggande dilemmat för denna reflektion - hur man kan entusiasmera studenter inför uppsatsskrivandet och samtidigt kommunicera att det kommer att innebära hårt arbete att klara av det - kan till exempel förstås i relation till det stöttningsmål van de Pol et al. betecknar som recruitment (van de Pol et al., 2010:278), vilket i deras definition omfattar att få studenter intresserade av en uppgift och samtidigt hjälpa dem hantera de krav som uppgiften omfattar.

Deras betoning av att stöttning måste inkludera aktivitet från både lärare och student, och dessutom bygga på contingency, det vill säga att lärarens agerande utgår från studenternas förkunskaper, kan i sin tur säga något om varför det här dubbla målet inte alltid var så enkelt att få till i praktiken (van de Pol et al., 20IO:274-276). Även om jag till exempel försökte bygga vidare på studenternas förkunskaper under introduktionsföreläsningen genom att knyta an till vad de hade gjort på tidigare kurser på programmet och på sin VFU, gjorde förutsättningarna att detta blev ett mycket oskarpt verktyg. Dels för att de drygt hundra studenter jag talade till befann sig på olika nivåer, där en del relativt enkelt kunde relatera till det jag talade om, medan det för andra kunde framstå som något nytt, obekant och stressande eller till och med skrämmande. Dels för att föreläsningskontexten i sig inte bäddar för någon större aktivitet från studenternas sida. Visst hade studenterna möjlighet att ställa frågor, och de utnyttjade som sagt också denna, 


\section{Maria Zackariasson}

men situationen vi befann oss $\mathrm{i}$ just där och då gjorde det svårt för studenterna att i någon större utsträckning ta aktiv del i stöttningsarbetet.

Men kursen innehöll förstås inte bara föreläsningar, och senare under uppsatsperioden fanns det större möjlighet att utgå från studenternas individuella kunskapsnivå, liksom för dem att vara aktiva i stöttningsarbetet. Inte minst i handledningssituationen förstås, som, om allt fungerar som det ska, kan vara en utmärkt arena för ett lyckat stöttningsarbete med aktivitet från både student och handledare och utgångspunkt i studentens kunskapsnivå och utveckling. Kursens uppläggning erbjöd också andra tillfällen till detta, till exempel genom obligatoriska seminarier, där studenterna under det första diskuterade och fick respons på sitt uppsats-pm, och under det andra gjorde samma sak med ett första uppsatsutkast. Att få respons på sitt arbete är ett av de stöttningsverktyg van de Pol et al. (2010:277) tar upp, och här vill jag särskilt lyfta fram att seminarierna gav studenterna möjlighet att inte bara få respons från seminarieledaren, även om det är viktigt, utan också att värdera och betrakta sitt eget arbete och sin egen utveckling i diskussion med andra studenter och genom att själv kommentera andras texter. Här var de således högst aktiva i stöttningsprocessen.

Båda seminarierna kan också ses som förberedelse för att studenterna så småningom skulle ta ansvar för att kritiskt granska någon annans text och kunna försvara sin egen, när det väl var dags för ventilering och opposition. Det tredje och sista obligatoriska seminariet på kursen handlade också explicit om just ventileringen och hur man genomför en opposition. Men här kan jag i efterhand se att det seminariet hade haft större potential att bidra till stöttning i van de Pol et al.:s mening, till exempel när det gäller lärarens tillbakadragande och det gradvisa överförandet av ansvar till studenterna, om det hade haft ett annat format (van de Pol et al., 20IO:275). I praktiken byggde det nu i alltför hög grad på information från seminarieledaren till studenterna om hur ventileringen skulle gå till och vad som är bra att tänka på när man ska förbereda och genomföra opposition på någon annans uppsats, vilket inte gav särskilt stort utrymme för varken studentaktivitet, eller att bygga vidare på det studenterna faktiskt lärt sig under kursen på något mer genomarbetat sätt.

\section{RELATIONEN MELLAN STRESS OCH STÖTTNING}

Uppsatskursen jag var ansvarig för hade således inslag som på olika sätt kan ses som led i ett stöttningsarbete. Men en generell aspekt av detta, som är värd att reflektera över, är att även sådana aktiviteter som har potential eller är tänkta att bidra till stöttningsprocessen kan uppfattas som stressande av studenterna. På just den här kursen kan seminarierna där uppsats-pm och uppsatsutkast diskuterades ses som ett exempel på det. Samtidigt som de kunde erbjuda goda möjligheter för studenterna att få respons på sitt arbete, som tog utgångspunkt $\mathrm{i}$ var de befann sig just då, liksom att själva delta aktivt i stöttningsarbetet genom att diskutera sina och andras texter med varandra, kunde seminarierna för vissa studenter av olika anledningar leda till negativ stress. Till exempel för de studenter som inte hunnit skriva det där utkastet $\mathrm{i}$ tid, eller som upplevde att deras egen text var markant mycket mer ofärdig än studiekamraternas när de diskuterade dem i responsgrupper. Den tänkta stöttningen kunde också leda till negativ stress om kommentarer och synpunkter framfördes på mindre pedagogiskt vis av seminarieledare eller studiekamrater eller för att studenten inte klarade av att ta emot och hantera kritik just där och då, kanske för att det hänt något på hemmaplan som påverkade hela situationen.

Även handledning, denna potentiellt goda arena för stöttningsarbete, har i många avseenden en tydligt stressande funktion. Målet med ett handledningsmöte är ju att få studenterna att tänka framåt, få dem att tänka igenom vad de behöver göra för att ro det hela i land, genom 
frågor om vad studenten tänker göra härnäst, vilka teorier eller metoder hen har tänkt använda eller hur hen ska hitta intervjupersoner och så vidare. Handledningsmötena kan således upplevas som stressande både för att de belyser vad som är nödvändigt för studenten att göra för att processen ska gå vidare, och för att de tydliggör vad studenten redan borde ha gjort. De tydliga deadlines för textutkast som seminarierna innebar kan också ses som både exempel på stöttning, såtillvida att de kan hjälpa studenten strukturera sin tid, och exempel på ett potentiellt stressande inslag i och med att tidsramarna och vikten av att arbeta effektivt för att bli färdig i tid tydliggörs och accentueras.

Här är det viktigt att framhålla att den här typen av stressande inslag i en uppsatskurs inte uteslutande handlar om att studenterna ska bli färdiga i tid, även om det som sagt är viktigt både för dem, för utbildningen och för lärosätet. När jag som kursansvarig, och andra som var inne på kursen, kommunicerade till studenterna de krav och höga förväntningar som ställdes på dem, var det också knutet till en förhoppning om att kunna bidra till att studenterna kunde utmanas, utvecklas och lyckas sträcka sig längre än de gjort tidigare under utbildningen (jfr Bain, 2004:83ff). De flesta handledare och lärare på kursen var mycket engagerade i studenterna och deras uppsatsvedermödor, och ville verkligen att de skulle lyckas så bra det bara gick utifrån deras olika förutsättningar. För min egen del tog sig detta engagemang uttryck bland annat $i$ att jag bemödade mig om att vara tillgänglig för studenterna och svara på allehanda frågor och funderingar från dem under kursens gång. Eftersom handledarna kunde vara inne på flera kurser eller program och kom från många olika ämnesbakgrunder, var de inte alltid lika insatta i vad som gällde för just den här kursen som jag som varit kursansvarig, handledare och examinator under flera år. Jag kunde därmed ge studenterna en annan typ av hjälp, och kunde dessutom vara en viktig resurs i de fall då handledningen, av olika orsaker, fungerade dåligt.

Min beredvillighet att svara på deras frågor och funderingar kan sättas i relation till ett annat av de stöttningsmål van de Pol et al. (2010:277) tar upp, frustration control, vilket omfattar att hålla studenter motiverade genom att förebygga eller minimera deras frustration. Även sådant som att skriva en tydlig och genomarbetad studiemanual kan ses som ett led i sådan frustrationskontroll. Målet med denna typ av stöttningsarbete är med andra ord att, om möjligt, minska studenternas negativa stress för att underlätta deras arbete och hålla dem motiverade. Men för mig som kursansvarig, och även andra lärare på kursen, kunde det ta mycket tid, kraft och energi att vara så engagerad i kursen och i studenternas väl och ve. Ibland kändes det som att det inte hjälpte hur mycket vi än försökte stötta och hjälpa - vissa studenter blev aldrig nöjda. Eller snarare - de blev inte nödvändigtvis nöjda med de svar de faktiskt fick, till exempel när dessa syftade mer till att hjälpa dem att komma framåt på egen hand än till att tala om för dem exakt hur de skulle göra.

Studenternas ibland till synes omättliga behov av hjälp och stöd skulle, ur ett visst perspektiv, kunna tolkas som en negativ konsekvens av det stöttningsarbete som pågick. Såtillvida att ett mycket aktivt stöttningsarbete potentiellt sett skulle kunna leda till att studenterna fokuserar för mycket på den hjälp de kan eller upplever sig ha rätt att få från andra, och förbiser att uppsatsskrivandet i mångt och mycket innebär en ny roll för dem som studenter, där det finns mycket större krav på att de ska vara drivande och själva fatta de avgörande besluten (jfr Light et al., 2009:I54f). Samtidigt skulle det, ur ett annat perspektiv, kunna förstås som ett tecken på att det fanns för dåliga möjligheter för studenterna att själva vara delaktiga i processen. Att det blev för stort fokus på stöd och hjälp från de inblandade lärarna och handledarna, och för lite på studentens egen roll och aktivitet.

Ytterligare ett sätt att försöka förstå och förhålla sig till detta är genom att lyfta blicken och sätta uppsatsskrivandet i relation till hela den utbildning studenterna går. I det perspektivet kan 
uppsatskursen i sig ses som det steg där lärarna tydligast kliver tillbaka och lämnar över ansvaret till studenterna, det vill säga där van de Pol et al.:s (20IO) betoning av fading och transfer of responsibility, på allvar kan ske. Samtidigt kan just en sådan överlämning av ansvaret, som märks bland annat i de ökade kraven på självständighet, som sagt vara en av de saker som blir mest stressande för studenterna. För att undvika det bör stöttningsarbetet förstås ha påbörjats långt före uppsatskursen och funnits med som en kontinuerlig del under utbildningen, så att studenterna står väl rustade när de väl når det självständiga arbetet och förväntas, och tvingas, ta mer ansvar. När den potentiellt positiva stress uppsatskursens krav och förväntningar skulle kunna innebära övergår till negativ stress och oro och en vilja hos studenterna att få enkla svar på hur de ska göra, kan det med andra ord ses som ett tecken på att utbildningen inte i tillräcklig utsträckning förberett dem för detta ökade ansvar och självständighet.

\section{AVSLUTANDE REFLEKTIONER}

På den kurs som fått bli exempel i mina reflektioner runt hur man ska kunna entusiasmera och motivera studenter när det gäller uppsatsarbetet, samtidigt som man lyckas förmedla till dem att det kan vara en svår process, fanns det som sagt inte en genomtänkt och genomarbetad plan för hur stöttning skulle kunna genomsyra hela kursen, även om det fanns en hel del inslag som skulle kunna ses som beståndsdelar i ett stöttningsarbete enligt van de Pol et al.:s (20I0) definition. Det är förstås något som kan och bör utvecklas. Men i ett mer övergripande perspektiv går det inte att bortse från att det självständiga arbetet är och förblir en frustrerande och stressande process för många, just för att det ställs nya krav på självständighet och eget ansvar som inte alltid är lätta att hantera. I och med att detta är en grundförutsättning för de självständiga arbetena, kan det vara svårt att komma åt sådan negativ stress, oavsett hur mycket och väl genomtänkt stöttningsarbete som sätts in eller hur mycket lärarna på eller ansvariga för kursen försöker entusiasmera och motivera studenterna. Även om hela utbildningen idealt sett borde ha förberett studenterna så väl att detta inte skulle behöva vara ett problem, är det i praktiken ett dilemma, eller en potentiell konflikt, som man som ansvarig för kurser där studenter ska skriva självständiga arbeten som regel måste lära sig att leva med.

Tanken med den här texten är således inte att hitta en universallösning för hur uppsatskurser bör utformas för att minska studenters negativa stress, till exempel genom en viss sorts stöttningsarbete. Men jag menar att det finns en poäng i att reflektera runt den här typen av frågor och dilemman, om inte annat för att öka medvetenheten om de pedagogiska och organisatoriska val vi gör och hur dessa i sin tur påverkar både den enskilda lärarens eller kursansvarigas handlingsutrymme och studenternas upplevelse av och attityd gentemot den kurs de går. Jag ska avsluta med att lyfta fram några av de insikter mina reflektioner över just denna kurs bidragit med för mig.

Till att börja med vill jag lyfta fram insikten om att den stress och frustration studenter kan uppleva under uppsatsarbetet kan vara potentiellt positiv, i bemärkelsen att den kan uppstå av att individen genomgår personlig utveckling eller att kursen faktiskt leder till ett djuplärande (jfr Bain, 2004; Ramsden, 2003). Samtidigt är det viktigt att uppmärksamma att uppsatsprocessen också genomsyras av stress i mer negativ bemärkelse, såtillvida att studenterna ständigt påminns om att de inte har så mycket tid på sig, och att det ställs höga krav på dem och på den färdiga produkten. I den bästa av världar kan den typen av stress också fungera som stöttning, om den kan få studenterna att inse sådant som att de själva måste vara aktiva i att strukturera och planera sin tid för att hinna klart, och om vi lyckas förmedla till dem att vi har tilltro till att de kommer att ta ett betydelsefullt steg framåt och göra något utöver det de har gjort tidigare. 
$\AA ̊$ andra sidan kan även åtgärder som har potential att fungera som stöttning i vissa fall leda till negativ stress och oro. som kanske till och med hindrar studenterna i deras utveckling och arbete. Här är insikten alltså att potentiella stöttningsverktyg faktiskt kan bli stressframkallande i sig och, i värsta fall, stjälpa snarare än hjälpa. För att undvik detta finns det en poäng i att reflektera runt vilken effekt de åtgärder vi sätter in under en kurs kan ha, och hur de förhåller sig till varandra. Bygger de på studenternas förkunskaper och anpassas till var de befinner sig just då? Ges studenterna möjlighet att själva vara aktiva och delaktiga i stöttningsarbetet? Kliver vi faktiskt tillbaka och ger dem större ansvar mot slutet? Gör vi det gradvis - helst under hela utbildningens gång så de är väl förberedda när uppsatskursen kommer och de förväntas ta ett stort eget ansvar? Om inte - vad kan vi göra annorlunda?

Viktiga frågor att reflektera runt och till synes självklara mål att sträva efter. Men samtidigt krävs en hel del realism. Även om stöttning, i den här mer specifika betydelsen, på många sätt framstår som väl värt att sträva efter i planeringen och genomförandet av uppsatskurser, gör kontextuella faktorer att det kan vara svårt att genomföra detta fullt ut. Det är till exempel betydligt lättare att få till individanpassning, eller att göra studenterna verkligt delaktiga, på små uppsatskurser med ett fåtal deltagare, jämfört med i de stora kullar det kan vara på lärarutbildningsprogram och andra studentrika utbildningar. Förutsättningarna för att väcka och upprätthålla studenternas entusiasm under arbetet med de självständiga arbetena måste också sättas i relation till de förväntningar och krav som finns på detta, när det gäller självständighet, eget ansvar och att driva projektet framåt, krav som i sig kan leda till att vissa studenter blir modfällda och desillusionerade i frustration över en ny och svårbemästrad situation. Sådan frustration och uppgivenhet, som är knuten till det självständiga arbetets grundläggande förutsättningar, torde, som sagt, vara svår att komma tillrätta med även med ett mycket väl genomfört stöttningsarbete på en kurs.

\section{FÖRFATTARPRESENTATION}

Maria Zackariasson är professor i etnologi vid Södertörns högskola, Stockholm. Hennes forskning har huvudsakligen rört sig inom två fält. Dels ungas samhällsdeltagande och engagemang genom sociala rörelser och ungdomsorganisationer, dels olika aspekter av högre utbildning, senast i ett mångvetenskapligt forskningsprojekt om självständighet och uppsatshandledning. Zackariasson har undervisat inom etnologi och lärarutbildning och är sedan 2016 forskningsledare för lärarutbildningen på Södertörns högskola.

\section{REFERENSER}

Bain, K. (2004). What the best college teachers do. Cambridge: Harvard University Press.

Barkat, J. C. G. (2014). Handing over the baton: An intervention study looking at improving students' motivational attitudes towards taking greater ownership of their learning at KS4. London: University of London.

Bodrova, E., \& Leong, D. J. (1998). Scaffolding emergent writing in the zone of proximal development. Literacy Teaching and Learning, 3(2), 1-18.

Castello, M., Inesta, A., \& Monereo, C. (2009). Towards Self-Regulated Academic Writing: An Exploratory Study with Graduate Students in a Situated Learning Environment. Electronic Journal of Research in Educational Psychology, 7(3), 1107-1130.

Castillo-Montoya, M. (2018). Rigor Revisited: Scaffolding College Student Learning by Incorporating Their Lived Experiences. New Directions for Higher Education (181), 37-46. doi:10.1002/he.20269

Clegg, S. (2000). Knowing through reflective practice in higher education. Educational Action Research, $8(3), 451-469$

Cotterall, S. (2013). More than just a brain: emotions and the doctoral experience. Higher Education Research and Development, 32(2), 174-187. 


\section{Maria Zackariasson}

Ekholm, D. (2012). Handledning av examensarbeten som lärande i the zone of proximal development. Högre Utbildning, 2(2), 67-78.

Feldt, R. C., \& Updegraff, C. (2013). Gender Invariance of the College Student Stress Scale. Psychological Reports, 113(2), 486-489. doi:10.2466/03.PR0.113x23z0

Galbraith, N. D., \& Brown, K. E. (2011). Assessing intervention effectiveness for reducing stress in student nurses: quantitative systematic review. Journal of Advanced Nursing, 67(4), 709-721. doi:10.1111/ j.1365-2648.2010.05549.x

Healey, M. (2005). Linking research and teaching: exploring disciplinary spaces and the role of inquiry-based learning. I R. Barnett (red.), Reshaping the University: New Relationships between Research, Scholarship and Teaching (s. 67-78). Maidenhead: McGraw Hill / Open University Press.

Kicken, W., Brand-Gruwel, S., \& van Merriënboer, J. J. G. (2008). Scaffolding advice on task selection: a safe path toward self-directed learning in on-demand education. Journal of Vocational Education \& Training, 60(3), 223-239. doi:10.1080/13636820802305561

Knight, R.-A., \& Botting, N. (2016). Organising undergraduate research projects: student-led and academicled models. Journal of Applied Research in Higher Education, 8(4), 455-468. Doi:10.1108/JARHE-07-2015-0054

Korhonen, A.-M., Ruhalahti, S., \& Veermans, M. (2018). The online learning process and scaffolding in student teachers' personal learning environments. Education and Information Technologies, 1-25. doi:10.1007/s10639-018-9793-4

Light, G., Cox, R., \& Calkins, S. (2009). Learning and teaching in higher education : the reflective professional (2 uppl.). London: Sage.

McCormack, C. (2009). Postgraduate research students' experience: It's all about balancing living. I M. Tight, K. H. Mok, J. Huisman, \& C. Morphew (red.), The Routledge International Handbook of Higher Education (s. 181-193). New York \& London: Routledge.

Mills, S., Krouse, A. M., Rossi-Schwartz, R., \& Klein, J. M. (2017). Curriculum revision: Student stress and lessons learned. Journal of Nursing Education, 56(6), 337-342. doi:http://dx.doi.org/10.3928/ 01484834-20170518-04

Ramsden, P. (2003). Learning to teach in higher education (2. uppl.). London: RoutledgeFalmer.

Thoonen, E. E. J., Sleegers, P. J. C., Peetsma, T. T. D., \& Oort, F. J. (2011). Can teachers motivate students to learn? Educational Studies, 37(3), 345-360. doi:10.1080/03055698.2010.507008

Todd, M. J., Smith, K., \& Bannister, P. (2006). Supervising a social science undergraduate dissertation: staff experiences and perceptions. Teaching in Higher Education, 11(2), 161-173. doi:10.1080/ 13562510500527693

van de Pol, J., Volman, M., \& Beishuizen, J. (2010). Scaffolding in Teacher-Student Interaction: A Decade of Research. Educational Psychology Review, 22, 271-296. doi:10.1007/s10648-010-9127-6

Wass, R., Harland, T., \& Mercer, A. (2011). Scaffolding critical thinking in the zone of proximal development. Higher Education Research \& Development, 30(3), 317-328.

Zackariasson, M. (2018). 'I feel really good now!' - Emotions and independence in undergraduate supervision. Learning and Teaching: The International Journal of Higher Education in the Social Sciences, 11(3), 1-24. doi:10.3167/latiss.2018.110303 